\title{
Secured Fingerprint-enabled Keyless Motorcycle Authentication System using Arduino
}

\author{
Maynard Gel F. Carse \\ San Carlos College \\ Abanon, San Carlos City \\ Pangasinan, Philippines
}

\author{
Jerome V. Custodio \\ San Carlos College \\ Tarectec, San Carlos City \\ Pangasinan, Philippines
}

\author{
John Vic S. Verzosa \\ San Carlos College \\ Quezon Blvd., San Carlos \\ Pangasinan, Philippines
}

\begin{abstract}
In the past years, the numbers of motornapping had increased. A total of 46,467 motorcycles were reported stolen in 2016 compared to 45,555 reported in 2015 (Velasquez, 2014). Because of risen numbers of motornapping, the proponents proposed secured fingerprint-enabled keyless motorcycle authentication system using arduino to stop and minimize the number of motornapping in the Philippines. Upon the evaluation, 20 evaluators agreed that the mobile application has a user authentication and 20 evaluators agreed that the motorcycle connects via bluetooth. About the ignition of the motorcycle, 20 of them agreed that the application can control the master ignition of the motorcycle. Whereas 20 of the evaluators agreed that the mobile application can turn on the engine as well as the use of the fingerprint scanner.
\end{abstract}

\section{Keywords}

Authentication system, Arduino, Bluetooth, Perimeter detection alarm, Fingerprint-enabled, Keyless motorcycle

\section{INTRODUCTION}

1The Philippines is one of the countries in Southeast Asia with many motorbike users. In almost every street, every corner, every road-big or small, for sure, there is a motorcycle rider just speeding his way and avoiding Philippines 'fatal' traffic situation. As a result of its sudden rise in numbers, motorcycles or motorbikes have recently been the common target of thieves. The system will help many motorcycle users to secure and feel comfortable without looking back to their motorcycle because of its security features and anti-thieves fingerprint-enabled ignition feature. By doing this project, it clearly shows that a variety of security can be added to the motorcycle.

Imagine the world with the motorcycle locking and starting engine by using mobile Bluetooth technology or fingerprintenabled will be a great advantage in terms of human energy and time-consuming. Therefore, this system consists of an android based mobile application on an Android device that connects wirelessly using Bluetooth to the Arduino system that acts as the microcontroller. The system is constructed by integrating both hardware and software.

In this project, proponents present an advanced security system for motorcycles. As there is a tremendous increase in sales of motorcycles but also the counter of stolen vehicles rapidly increases. Nowadays usually to prevent theft of normal locks and wireless key, these are the two options available in the market. But the proposed system is designed such that there is no need for any keys. The proposed security system is totally based on the fingerprint secured fingerprint- enabled keyless motorcycle authentication system using Arduino. The idea of this project came when there are a lot of cars today uses a wireless security system and different technologies. But, the security system for motorcycle, especially outdated bikes were not developed as well as the cars.

\section{RELATED LITERATURE}

3Aside from the Arduino module, other add-ons such as fingerprint module and Bluetooth can be used to make the security reach even greater heights. Based on the study of, taking the help of Adafruit library and open source Arduino IDE, the proponents can develop source code without the hassle of the internal architecture of the fingerprint module. The fingerprint is one of the hardest information to copy because people have different fingerprint.4Even current technologies have no fingerprint copying application. Fingerprints have remarkable permanency and uniqueness throughout the time. Fingerprint ignition is effective because when someone tries to start the motorcycle, it will not work because only the authorized fingerprint can start the motorcycle. The proponents could make it possible with the help of Arduino fingerprint ignition which will be applied in the motorcycle.

The connection between the motorcycle and the keyless ignition system can be done through the use of Bluetooth module. The Bluetooth will serve as a monitoring device when the connection between the motorcycle and the mobile application disconnects, a notification will be sent to the owner.5The same idea was done by Vyas, et. al. in their study wherein Android smartphone with Bluetooth functionality was used to a run client-side application to gain access and control on the ignition system. This feature will prevent any thief from stealing the motorcycle by pushing it or carrying it away. This feature added extra security on the fingerprintenabled ignition of the project.

6Study of Shaharuddin reveals that a system can ignite the car anytime in the distance range between 0-10 meter radius using the Bluetooth module. In addition, the equipment parts used are the Rabbit Core Module (RCM3200) with the Prototyping Board (RCM3100) which is the heart of the created framework, the Embedded Blue (eb506) and Mobile Phone as a communication gadget. Combination of these technologies will enable the proposed project to have perimeter sensing and monitoring of the motorcycle. 


\section{PRESENTATION AND ANALYSIS OF DATA}

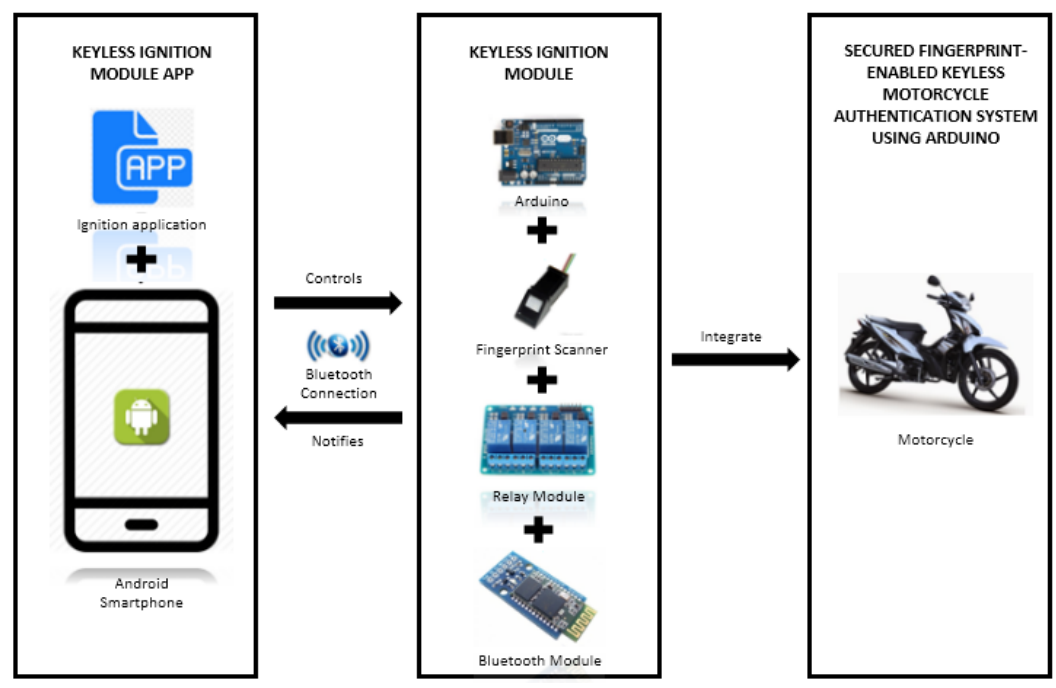

Fig 1. Operational Framework for the Proposed Project

Fingerprint-enabled keyless Motorcycle eliminates the motorcycles ignition key switch and all the hassles associated with using a key. It provides convenience and security. Fingerprint requires the physical presence of the person to be identified. This emphasizes its preference over the traditional method of having such as keys, smartcard, and passwords, etc. Also, it prevents unauthorized authentication to access control system.

The keyless ignition module is consisting of an Arduino, Bluetooth module, Fingerprint sensor, and a relay module. Arduino is the core or the main processor of the system where it can be programmed using the Arduino(IDE). The Bluetooth Module will act as wireless communication between the mobile application and the Arduino. And also with the fingerprint sensor connected to the Arduino, they can enroll and verify the user, and when the user is authorized the fingerprint scanner will trigger the Relay Module where Relay Module will act as the switch that is connected to the motorcycle ignition mechanism. Smartphone basically act as the remote of the keyless ignition module where a mobile application installed specifically designed to remotely controls the keyless ignition module.

\section{PRESENTATION AND ANALYSIS OF DATA}

\subsection{Description of the Project}

This project aims to reduce or avoid motornapping in the country. This project could help motorist to secure their motorcycle against motornapping. The project includes features like keyless fingerprint ignition system. The project has a fingerprint module that allows the user to start the

motorcycle without using a key. Another, a Bluetooth module that allows the user to connect to the motorcycle via mobile phone that contains a mobile application that can start the motorcycle. It also has Bluetooth perimeter feature that when the motorcycle is being pushed away or being carried; disconnection will be notified to the user and will automatically alarm so that the owner will feel secured and can prevent motornapping.

\subsection{Development}

After gathered and analyze the requirements it is time to build and develop the project. The proponents start to connect all the dupont wires to the breadboard, pins of Arduino and relay module. The proponents also start to program the system of the Arduino, and also the proponents start to make a mobile application for the Secured Fingerprint-enabled Keyless Motorcycle Authentication System Using Arduino.

\subsection{Design}

The mobile application aim is to give the user the ability to turn on and off their motorcycle. It features password security, motorcycle control, and an alarm monitor. At the start of the mobile application, the user needs to $\log$ in with the right credentials. In the next screen, the user can control the toggle switch of the ignition key and the start button. In addition, the user can customize the desired notification tone through the mobile application.

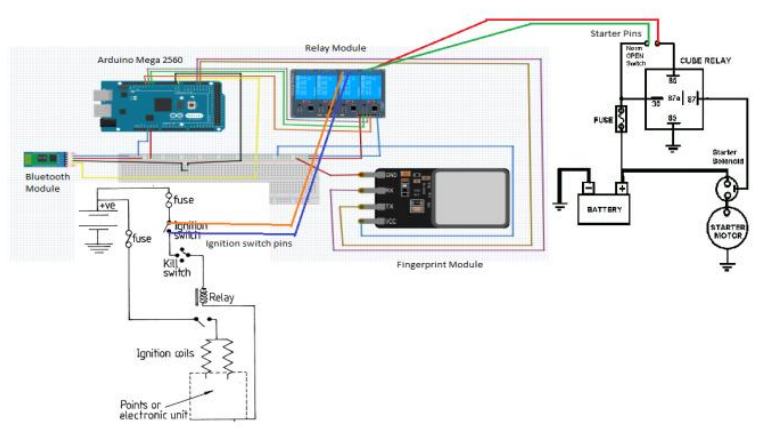

Fig 2 - Microcontroller to module diagram

Figure 2 shows the diagram on the possible wirings of the microcontroller and modules. Existing motorcycle mechanism, motorist tends to say that the ignition key is easy to use but it can be easily tampered key can be duplicated using standard keys, unlike cars that even the key is duplicated it will not work because of the additional features such as a transponder chip. In addition, mechanical keys tend to rust after a while

\subsection{Snapshot / Wireframe}

A wireframe is a visual guide that represents the skeletal framework of a website, indicating where visual and UI components are located (technopedia). 

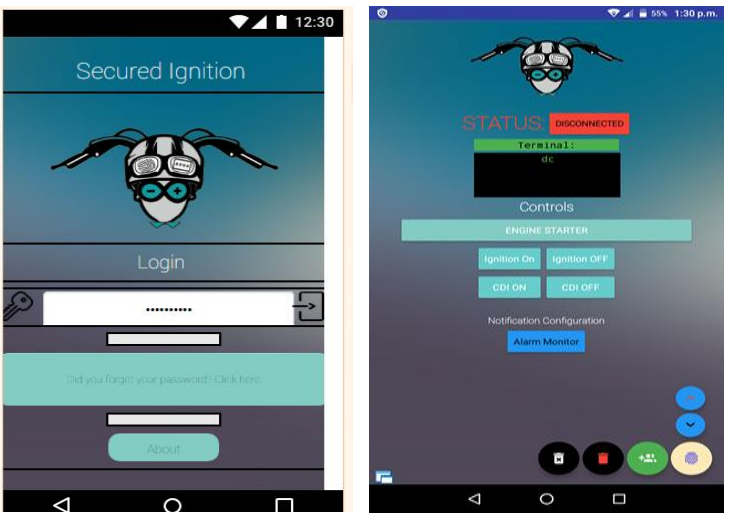

Fig 3 - Log in and Control Screen

In the login control screen, the proponents make the user interface simple so that the user can use the application with ease. On top of that, the proponents added a screen terminal so that when the user tries to enroll another user, the user can read the instructions for enrolling or deleting a user ID.

\subsection{Implementation}

After the proponents removed the case of the motorcycle the proponents ready the system to be installed inside the bikes Ubox after the installation of the system. The proponents conduct a series of drive tests and the proponents were able to find out the errors in the design of circuitry.

The proponents were able to find an enclosure for the system for the safety of the circuitry and to make the system compact. The hardware and arrangement of the sensors were assembled inside the bike's utility box Putting them inside the utility box will lessen the probability of the circuitry being exposed to water because of rain or other water sources.

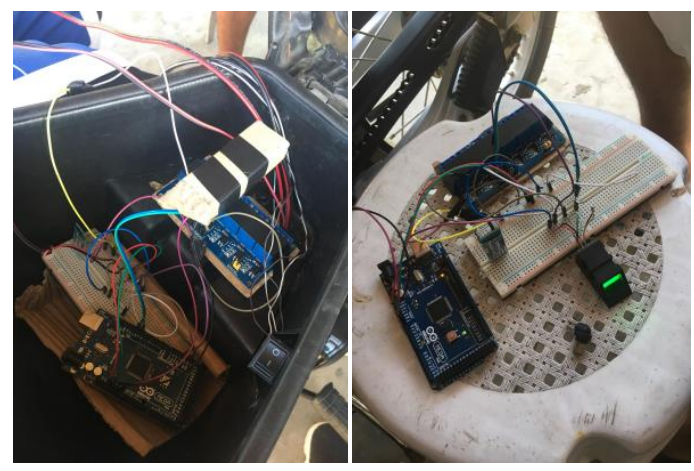

Fig 4- Installation in the Utility Box

\section{RESULTS, CONCLUSION, AND RECOMMENDATION}

\subsection{Testing}

In this area, the proponents analyze the results from the survey form. Survey is conducted from different types of users such as motorist, hobbyist and motor dealers. Results for the functionality and usability of the project from the users. The proponents prove that their project is successful because of the answers of respondent in the survey questionnaire.

\section{Motorcycle User, Hobbyist, Dealers Evaluation Result}

\begin{tabular}{|c|c|c|}
\hline Questions & YES & NO \\
\hline $\begin{array}{c}\text { Does the mobile application authenticate } \\
\text { user before using it? }\end{array}$ & 20 & 0 \\
\hline $\begin{array}{l}\text { Does the mobile application connects to } \\
\text { the motorcycle via Bluetooth? }\end{array}$ & 20 & 0 \\
\hline $\begin{array}{l}\text { Does the application controls the master } \\
\text { ignition of the motorcycle? }\end{array}$ & 20 & 0 \\
\hline $\begin{array}{c}\text { Does the motorcycle starts using the } \\
\text { mobile application? }\end{array}$ & 20 & 0 \\
\hline $\begin{array}{l}\text { Does the motorcycle recognizes } \\
\text { authorized user using fingerprint module? }\end{array}$ & 20 & 0 \\
\hline $\begin{array}{l}\text { Does the motorcycle starts through } \\
\text { fingerprint module? }\end{array}$ & 20 & 0 \\
\hline $\begin{array}{l}\text { Does the motorcycle stops when } \\
\text { unrecognized fingerprint was used? }\end{array}$ & 19 & 1 \\
\hline $\begin{array}{l}\text { Does the application able to stop the } \\
\text { motorcycle? }\end{array}$ & 20 & 0 \\
\hline $\begin{array}{c}\text { Does the mobile application notify the } \\
\text { owner when motorcycle is beyond } \\
\text { monitoring radius? }\end{array}$ & 20 & 0 \\
\hline $\begin{array}{l}\text { Does the application able to add new user } \\
\text { to the motorcycle's fingerprint module? }\end{array}$ & 20 & 0 \\
\hline $\begin{array}{l}\text { Is the mobile application easy to use and } \\
\text { understand? }\end{array}$ & 20 & 0 \\
\hline $\begin{array}{l}\text { Does the keyless ignition feature hassle- } \\
\text { free to motorcycle users? }\end{array}$ & 20 & 0 \\
\hline Does the system secure the motorcycle? & 20 & 0 \\
\hline $\begin{array}{c}\text { Can the mobile application be use } \\
\text { anytime? }\end{array}$ & 20 & 0 \\
\hline $\begin{array}{l}\text { Is the mobile application free from } \\
\text { runtime error or unwanted behavior? }\end{array}$ & 20 & 0 \\
\hline $\begin{array}{l}\text { Does the mobile application work on any } \\
\text { android phones? }\end{array}$ & 20 & 0 \\
\hline
\end{tabular}


To fix the problem in question number 7 the proponents found out that the fingerprint scanner is sensitive to lights that can trigger fingerprint scanning feature even the motorcycle is running when the lights reach the fingerprint scanner the motorcycle will turned off in that case it is dangerous it will cause accident so that the proponents change it to only registered fingerprint can turn off the motorcycle.

\subsection{Conclusion}

The implementation of the project will not only reduce the risk of the motorcycle being stolen, but this can also help the motorist free of carrying a key that can be lost or tend to break. With the use of the keyless ignition, the motorist was able to start the engine with ease. The results of the testing show that the proponents were able to successfully implement the system without any runtime errors. This system may reduce the risk of fraudulent activities on the motorcycle such that only registered fingerprint user can use the motorcycle. During the development of the project, the proponents found out that several motorcycle brands use similar types of the ignition key.

Overall, the project earned a high percentage of "yes" in the conducted evaluation. All 16 question has an average of $99.69 \%$ or 319 out of the 320 of the answers is "yes". While $0.31 \%$ of the evaluators disagreed at one of the evaluation questions.

\subsection{Recommendation}

The project is designed and implemented on a motorcycle with a utility box. In the future, the proponents should consider adding a design and enclosure specifically for a motorcycle that has no utility box.

Since implementing the proposed system to the motorcycle is a bit complicated and some motorists are not happy dismantling motorcycle covers, the proponents recommend that a convenient connector is placed on a conspicuous area for easy implementation.

The proponents recommend that the fingerprint module is mounted on a place where it will not be vulnerable to rain and sunlight because it can trigger the scanning function of the module.

\section{REFERENCES}

[1.] Reyes., 2017. Cases of Motornapping / Bikenapping in the Philippines. https://ichoose.ph/blogs/casesmotornapping-bikenapping-philippines/

[2.] Velasquez, 2014. https://www5.topgear.com.ph/motosapiens/motorcycle-news/pnp-report-carnappingmotorcycle-theft-a00188-20170815?ref=article_tag

[3.] Ronak M/ Vithlani., 2016. Biometric automobile ignition locking system. https://www.researchgate.net/publication/318283894_BI OMETRIC_AUTOMOBILE_IGNITION_LOCKING_S YSTEM

[4.] Amit Saxena, Sarthak Sharma, Shivam Gaur, Shubham Chauhan, Shantanu Varshney., 1985. Ignition Based on Fingerprint

Recognition.http://www.ijsrms.com/media/8I13IJSRMS0201663-v2-i1-66-71.pdf.

[5.] Haider A, Anwer A, Khan H, Denai M,. 2017. A smart wireless car ignition adv automob. https://www.longdom.org/open-access/a-smart-wirelesscar-ignition-system-for-vehicle-security-2167-76701000169.pdf

[6.] Muhamad Zulhaziq Bin Mohd Shaharuddin.,1995. Wireless security for bike ignition using android via Bluetooth.http://eprints.utem.edu.my/18427/1/Wireless\% 20Security\%20For\%20Bike\%20Ignition\%20Using\%20A ndroid\%20Via\%20Bluetooth.pdfC. J. Kaufman, Rocky Mountain Research Lab., Boulder, CO, private communication, May 1995.

[7.] Simon., et al. 1997. Keyless motor vehicle entry and ignition system. https://patentimages.storage.googleapis.com/aa/5a/37/a0 5daee4fbc48b/US5937065.pdf

[8.] Vyas et al,. 2016. Access control application using android smartphone, arduino Bluetooth. DOI: 10.5120/ijca2016909902 